This item was submitted to Loughborough's Research Repository by the author.

Items in Figshare are protected by copyright, with all rights reserved, unless otherwise indicated.

\title{
Experimental assessment of vapour chamber heat spreader implementation in avionic cooling
}

\section{PLEASE CITE THE PUBLISHED VERSION}

http://dx.doi.org/10.2514/6.2015-0712

\section{PUBLISHER}

(c) American Institute of Aeronautics and Astronautics

\section{VERSION}

AM (Accepted Manuscript)

\section{PUBLISHER STATEMENT}

This work is made available according to the conditions of the Creative Commons Attribution-NonCommercialNoDerivatives 4.0 International (CC BY-NC-ND 4.0) licence. Full details of this licence are available at: https://creativecommons.org/licenses/by-nc-nd/4.0/

\section{LICENCE}

CC BY-NC-ND 4.0

\section{REPOSITORY RECORD}

Jones, Andy, Rui Chen, and Angus Murray. 2016. "Experimental Assessment of Vapour Chamber Heat Spreader Implementation in Avionic Cooling". figshare. https://hdl.handle.net/2134/20133. 


\title{
Experimental Assessment of Vapour Chamber Heat Spreader Implementation in Avionic Cooling
}

\author{
Andy Jones ${ }^{1}$, Rui Chen ${ }^{1 *}$, Angus Murray ${ }^{2}$
}

\begin{abstract}
Avionic thermal management is quickly becoming the limiting factor of aircraft performance and reliability, particularly prevalent with ageing airframes. While the increasing power density of avionic components requires a greater heat removal capacity for a given geometric module size, supplementary generation of cooling airflow is detrimental to engine and aircraft performance. This paper looks at improving the heat removal efficiency of forced convection cooled avionic modules by reducing the thermal resistance between the avionic component and module heat exchanger. The implementation of two-phase high thermal conductivity materials, such as Vapour Chamber Heat Spreaders (VCHS), embedded within the avionic module chassis act to improve heat exchanger isothermalisation, improving the effective heat transfer area. A bespoke test rig has been manufactured to experimentally compare a pure aluminium and embedded VCHS avionic chassis for heat removal capability. When considering a single circuit card, a direct mass flow rate reduction of between $22 \%$ and $65 \%$ is achieved with embedded VCHS over a pure aluminium chassis. Base plate isothermalisation is improved by $9 \%$, generating a reduction in component temperature of $8 \%$ to $12 \%$. As the number of heat sources increase, the performance improvements decrease. When testing with three circuit cards mass flow rate savings are reduced to between $14 \%$ and $26 \%$. The concluding performance characteristic of the embedded VCHS avionic base plate is the insensitivity to the way thermal energy is coupled to it. Across all testing, the localised heat removal was never further than $3.5 \%$ from the averaged plate performance.
\end{abstract}

\section{Introduction}

$\mathrm{M}$ ICROMINIATURISATION of electronic components and instrumentation of modern military aircraft has generated a substantial increase in avionic component power density. This trend is categorised by a high heat dissipation rate per unit of component area ${ }^{1}$. Customer requirements often demand the inclusion of emerging avionic capabilities within an airframe life-cycle as a result of a Mid Life Update (MLU) ${ }^{2}$. The retrospective fitment of increased power density electronic components without the modification of heat removal capacity generates an increase in operating temperatures. Continued operational cycling of avionic components above the thermal design limit has been proven to generate an exponential decay in component reliability ${ }^{3}$. The resulting thermal failure is notoriously difficult to diagnose, often displaying minimal irreversible damage and clouded by the frequency of No Fault Found (NFF) failures in avionic equipment. A NFF failure is categorised as an operational failure that cannot be replicated or isolated in further testing or component analysis. This phenomenon is a serious consideration within the aerospace industry, contributing to more than $85 \%$ of all observed operational failures in aircraft electronics, costing over $\$ 10,000,000$ each year in exchanging avionic units due to this failure mechanism ${ }^{4,5,6}$.

\footnotetext{
${ }^{1}$ Loughborough University, Leicestershire, LE11 3TU, UK

${ }^{2}$ BAE Systems Military Air \& Information, Warton, Lancashire, PR4 1AX, UK

*correspondence author: r.chen@lboro.ac.uk
} 


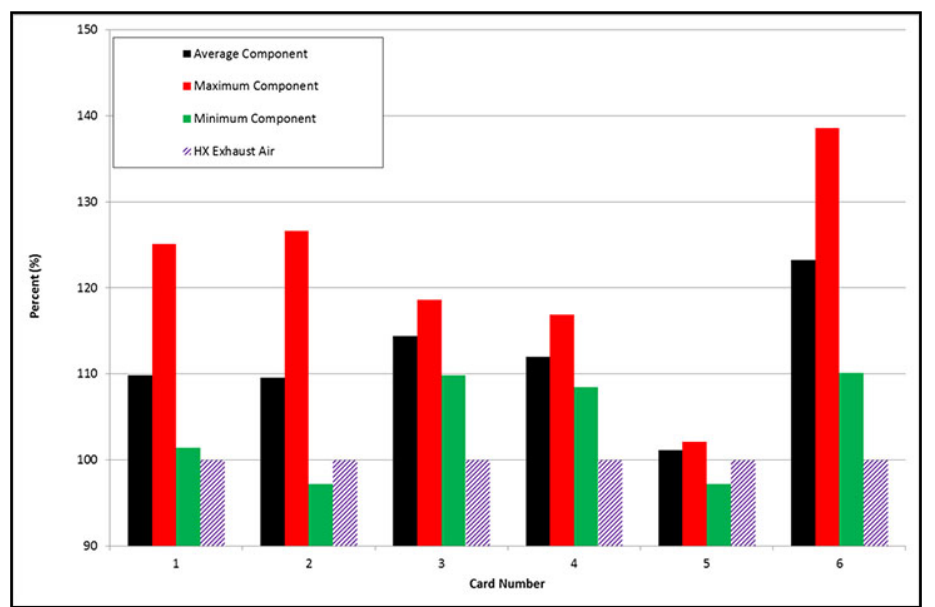

Figure 1: Thermal analysis of 6 circuit cards operating within a $1 / 2$ ATR conduction to cold wall avionic module.

Analysis of component temperatures inside a conduction to cold wall cooled avionic module presents evidence that a number of isolated components operate significantly hotter than the average avionic component temperature as detailed in Figure 1. The thermal analysis of six 21 Watt circuit cards mounted within a $1 / 2$ ATR (Air Transport Rack) module is displayed with the minimum, maximum and average component temperature of each circuit card presented as a percentage of avionic heat exchanger exhaust air temperature. While circuit cards $3,4 \& 5$ display a close relationship between component and exhaust air temperature, circuit cards 1,2 and 6 demonstrate localised conditions operating up to $38.6 \%$ hotter than exhaust air. The generation of such thermal hotspots is the result of high thermal resistance between the active component and avionic chassis heat exchanger, leading to irregular heat exchanger thermal loading. The aluminium avionic chassis base plate demonstrates poor isothermalisation and subsequently leads to reduced heat exchanger fin utilisation and diminishing heat removal efficiency with increasing mass flow rate.

Avionic thermal failure can be a function of isolated thermal hotspots, as opposed to an averaged saturation of heat removal capability. The aim of this investigation is to reduce the thermal resistance of the avionic chassis heat flow path through increased thermal conductivity of an avionic chassis base plate. This allows the cooling fluid to remove an equal amount of thermal energy across the entirety of the chassis heat exchanger, reducing the severity of thermal hotspots while increasing the effective heat transfer area. The measure of an improvement in isothermalisation is the minimisation of the variation between localised and plate averaged heat removal capacity.

\section{Avionic Thermal Management}

Typically, avionic cooling requirements dictate that no direct contact is made between the cooling fluid and the active electronic components; negating the risk of moisture ingress and contamination from ground debris often suspended within the airflow. The cooling medium is air, chosen for reliability and availability within the airframe. Avionic cooling takes a feed from the aircraft Environmental Control System (ECS), responsible for thermal management of aircraft subsystems which include cabin temperature \& pressure regulation, oxygen generation, demist system, wing de-icing, radar cooling and pilot anti-G suit pressurisation ${ }^{7}$. Although air cooling is unsuitable for high power density applications, it presents many advantages in avionic cooling. The aircraft carries a cold air generation system, imperative for pilot conditioning. The penalty of a system leak is minimised, as escaped air will bleed out through the aircraft skin. The danger of contamination, corrosion and moisture ingress to the electronic avionic components is omitted. The interchangeable avionic modules are easily integrated into the airframe cooling system using a basic rubber seal.

\section{A. Thermal Management Technologies}

Several studies have discussed the process of heat removal from forced convection cooled avionic modules, detailing configurations such as conduction to cold wall, air impingement cooling, flow through cooling, liquid immersion and jet impingement cooling ${ }^{8,9}$. Conduction to cold wall cooling is the preferred cooling process, detailed in Figure $2^{10}$. While other technologies such as flow-through and liquid immersion cooling offer greater heat removal efficiency; the increase in complexity, cost and difficulty of manufacture render these unsuitable. Additionally, these cooling techniques feature no direct thermal coupling between the active components and avionic chassis heat exchanger. As such, these cooling techniques are very sensitive to a reduction in cooling mass flow rate and demonstrate extremely poor performance in natural convection conditions. It is an essential criterion that the avionics must operate with a reduced airflow supply; as in the event of an ECS failure the pilot, cabin environment and flight critical components are prioritised.

$$
2
$$

American Institute of Aeronautics and Astronautics 


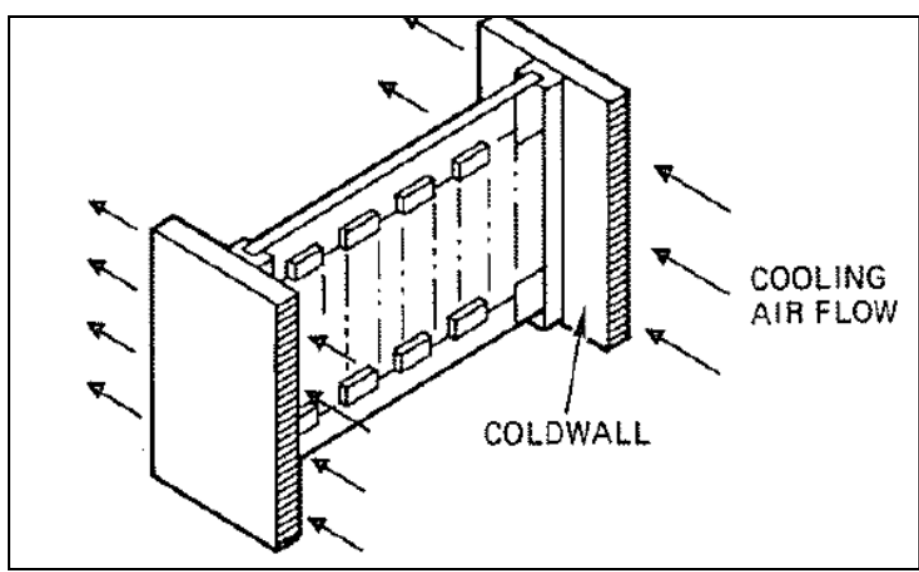

Figure 2. Conduction to cold wall avionic cooling. The heat flow path can be seen from the active components, through the circuit card and avionic base plate to the heat exchangers.

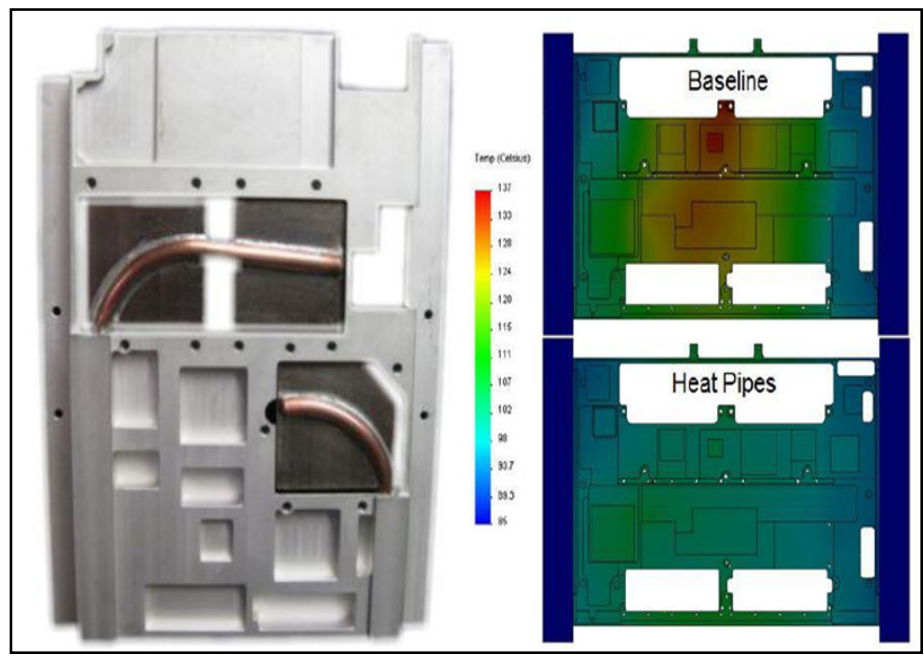

Figure 3. Embedded heat pipes for avionic cooling.

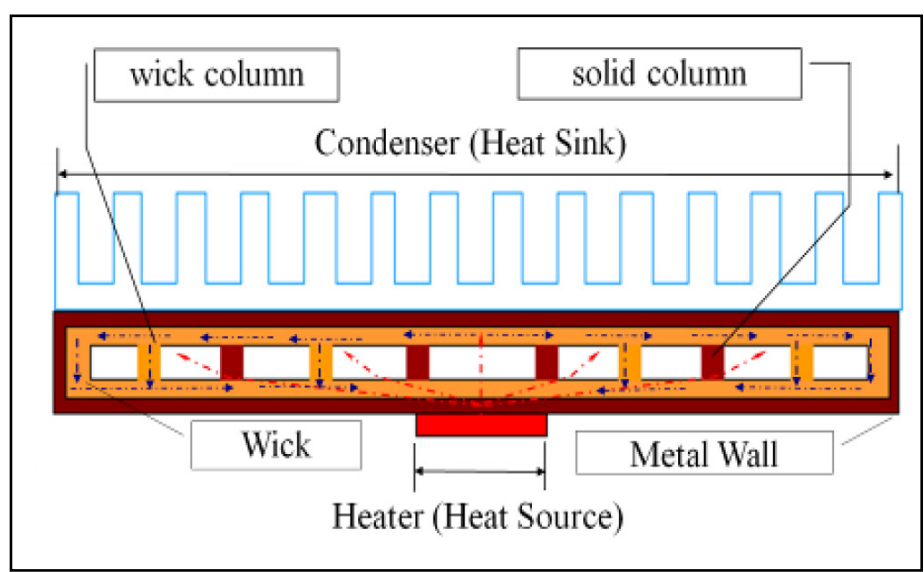

Figure 4. VCHS schematic diagram.
Embedded two phase thermal management technologies complement forced convection conduction to cold wall avionic modules and present in a number of options.

Embedded Phase Change Materials (PCM) melt and solidify at specific temperatures, with the capability to store and release large quantities of thermal energy. Latent heat energy absorbed by the PCM increases the bulk temperature above the material melting point and generates phase change to a liquid. Thermal energy is released as the material re-solidifies, making the technology suitable for highly transient thermal management applications where heat loads are variable with time, such as mobile phone cooling. The function of PCM is to store thermal energy for a finite period of time, before the energy can be released back into the system ${ }^{11}$. Although avionic modules do experience thermal cycling as a result of increased aircraft skin temperatures driven by frictional air resistance to forward flight, this is a secondary thermal loading. A thermal sensitivity study of the avionic bay conditions to flight conditions revealed that the primary thermal loading (avionic components) contributes the majority of avionic exhaust air temperature and hence should be prioritised, suggesting PCM is not suited to avionic thermal management optimisation.

The implementation of embedded heat pipes for avionic applications is seen in Figure $3^{12}$. An avionic circuit card is embedded with heat pipes to reduce the thermal resistance between the component and heat exchanger. Heat pipes utilise a continuous phase change cycle to transport thermal energy from a heat source to a heat sink. A heat source is used to vaporise a working fluid, generating a pressure gradient in the pipe. The vapour is driven to a heat sink under the pressure gradient, where thermal energy is removed from the pipe and the working fluid condenses back to a liquid. Typically the working fluid is returned to the heat source through a wick utilising capillary pumping forces, or under gravity. The transportation of thermal energy through phase change offers extremely high thermal conductivity, typically several magnitudes greater than aluminium. The strength of this technology is the ability to transfer a heat load from an isolated high energy heat source to a heat sink with very low thermal resistance, typically presenting a $2-5^{\circ} \mathrm{C}$ temperature drop across the length of a heat pipe.

The heat pipe embedded circuit card 
displayed a thermal conductivity of $500-1200 \mathrm{~W} / \mathrm{m} . \mathrm{K}$ in comparison to $167 \mathrm{~W} / \mathrm{m} . \mathrm{K}$ of a bare aluminium construction. The resulting temperature decrease of $28^{\circ} \mathrm{C}$ can be seen from the previously isolated thermal hotspot in the centre of the circuit card. While this thermal management technology is proven to be extremely effective, the design process requires detailed information on the configuration of the circuit card which is often proprietary. Therefore, this technology offers limited flexibility, with each embedded heat pipe configuration design specifically for use with a single circuit card configuration.

\section{B. Vapour Chamber Heat Spreaders}

A relatively new adaptation of heat pipes are Vapour Chamber Heat Spreaders (VCHS), seen in Figure 4. A VCHS is effectively a flat plate heat pipe, designed to utilise the high thermal conductivity of two phase heat transfer to increase the effective heat transfer area of isolated components. As with heat pipes, a heat source is used to evaporate the working fluid to a vapour, which is transported to a heat sink by an internal pressure gradient. The heat sink condenses the vapour back to a fluid, which is returned to the heat source through capillary pumping forces to repeat the cycle. The primary function of a VCHS is the efficient transportation of heat energy from a single isolated source to a large heat sink.

This passive two phase cooling cycle creates a plate of extremely high thermal conductivity, ideal for avionic applications. The capillary pumping forces through the wick ensure the cooling cycle operation in negative $G$ applications. The sealed unit has no risk of performance degradation through a supply or sealing issue. The operation of a VCHS is reduced when operating in sub-zero conditions, where freezing of the working fluid prohibits the vapour cycle and protects avionic components from over cooling. Most importantly the implementation of an embedded VCHS within an avionic chassis offers minimal disruption to conduction to cold wall cooling technique ${ }^{13,14,15}$. The aim of this investigation is to experimentally assess the application of this technology when coupled to multiple heat sources embedded within a representative real world avionic chassis.

\section{Embedded VCHS Test}

A sample of 2 VCHS (H,W,D: $122 \mathrm{~mm}, 87 \mathrm{~mm}, 3.3 \mathrm{~mm}$ ) have been supplied for this investigation. The VCHS features a fill ratio of $34 \%$ and a working fluid of distilled water, demonstrating a thermal conductivity of up to $5000 \mathrm{~W} / \mathrm{mK}$. A thermal image of the VCHS and Aluminium plate is shown in Figure 5. A back-to-back comparison is completed with each plate subjected to $30 \mathrm{Watts}$ from a heat source area of $0.00075 \mathrm{~m}^{2}$ located on the right hand side.

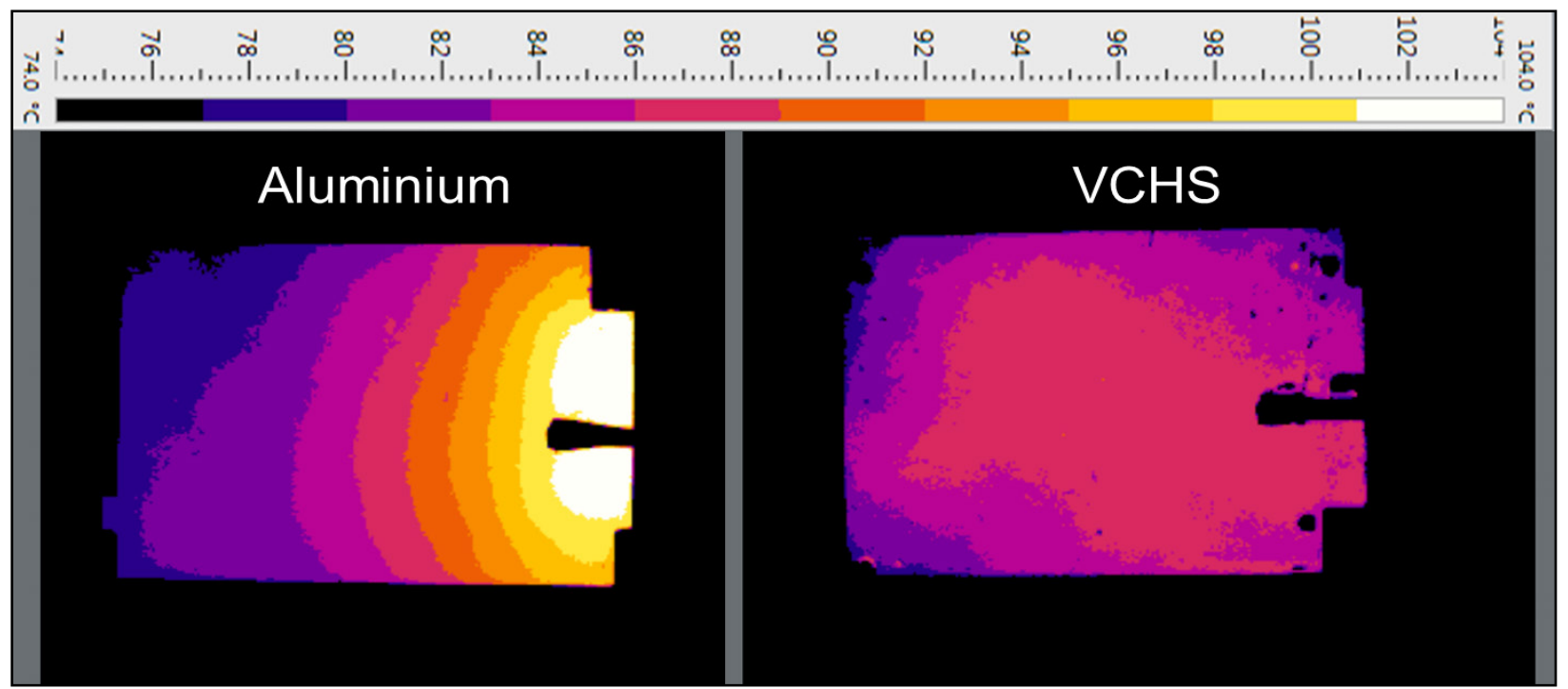

Figure 5: Thermal Image of a VCHS and Aluminium plates. The measured thermal conductivity from this test shows the $V C H S$ plate at $1481 \mathrm{~W} / \mathrm{mK}$ and the Aluminium plate at $206 \mathrm{~W} / \mathrm{mK}$.

The aluminium plate clearly demonstrates a lower thermal conductivity, indicating a localised hotspot around the heat source. The material temperature reduces linearly from the heat source across the length of the plate. The 
VCHS presents a much more equal temperature distribution, demonstrating a lower maximum temperature and a higher minimum temperature than the aluminium plate.

A test rig has been designed for the purpose of quantifying the heat transfer efficiency comparison between a pure aluminium avionic base plate and an embedded VCHS avionic base plate. The geometry and fin design has been matched exactly to a genuine in service 1/2ATR avionic module heat exchanger, with the exception of an increased thickness of $3 \mathrm{~mm}$ to the top plate to allow the implementation of VCHS. Experimentally, the power output and cooling flow characteristic will be supplied as per in-flight operation of these avionic modules. Typically a 1/2ATR chassis would exhibit a power output of 60 to 140 Watts depending on application, with a corresponding mass flow of $15 \mathrm{Kg} / \mathrm{hr}$. to $35 \mathrm{Kg} / \mathrm{hr}$. at a temperature of $15^{\circ} \mathrm{C}$ to $20^{\circ} \mathrm{C}^{7}$. A rig schematic can be seen in Figure 6 .

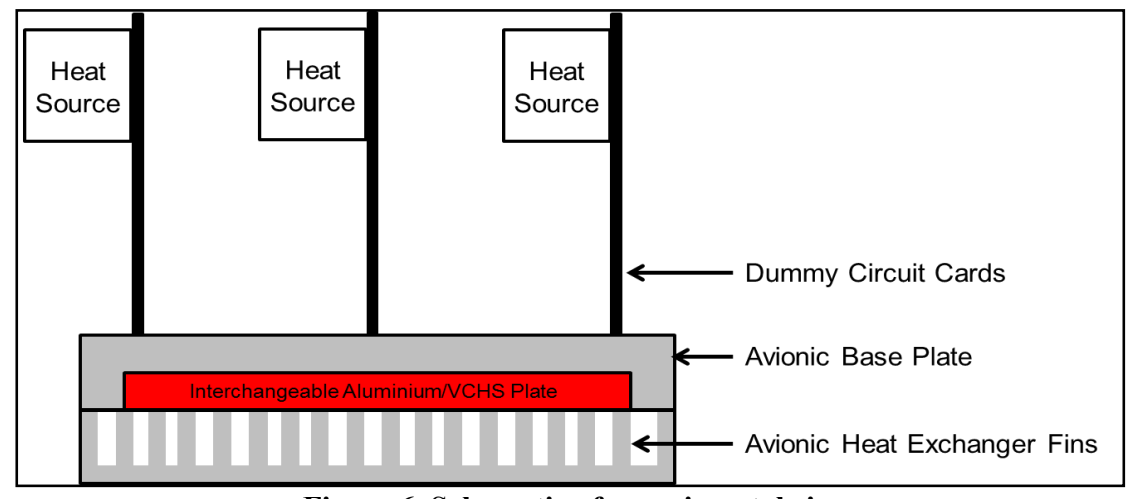

Figure 6. Schematic of experimental rig.

A mass flow rate is supplied at ambient laboratory temperature from an air fan with integrated smooth bell mouth inlet and venturi. The bell mouth inlet and venturi are used to ensure a measured and calibrated mass flow is supplied to the avionic chassis. The mass flow rate is calculated by process of measuring the pressure differential between the fan inlet throat and ambient air, assuming no losses across the smooth bell mouth intake.

As in the genuine operation, heater elements are thermally coupled to the circuit card which is mounted against the chassis cold wall. The rig allows a number of circuit cards to be used, with a comparison being made across 3 cards in this investigation. The heater power output is controlled by a variable desktop power supply.

All data acquisition channels are calibrated previous to testing. Temperature readings are taken with both individual thermocouples and a thermal camera. Thermocouple channels are calibrated against a known input voltage which aligns to a thermal input. The thermal camera, Flir A325, is manufacturer calibrated to an accuracy of $\pm 2 \%$ of the reading. Thermocouples will be used to measure the inlet airflow, component and exhaust airflow temperatures in seven locations.

Pressure transducers for mass flow calculation are subjected to a known pressure produced from a Druck 610SPC pressure calibration device. The linear response of the pressure transducer is measured and corrected across a span to be seen in experimental investigations. All instrumentation is measured using National Instruments LabView software.

\section{Results and Discussion}

The results for each case are expressed as a comparison of temperature and thermal energy removal efficiency. Comparative temperature study expresses localised exhaust airflow temperatures $\left(T_{L}\right)$ as a percentage of maximum exhaust airflow temperature $\left(\mathrm{T}_{\mathrm{Max}}\right)$. Comparative energy removal efficiency study expresses localised energy removal efficiency $\left(\mathrm{Q}_{\mathrm{L}}\right)$ as a percentage of plate averaged energy removal efficiency $\left(\mathrm{Q}_{\mathrm{Ave}}\right)$. The use of these two measures allows the understanding of the severity of thermal hotspot generation and a measure of plate isothermalisation. 


\section{A. Single Circuit Card}

Initially both avionics chassis were tested with a single dummy circuit card mounted at the extremity of the base plate in the orientation of cooling airflow. The small heat transfer area generated by a single card replicates a significant thermal hotspot, similar to the conditions generated by circuit card 6 as shown in Figure 1. Figure 7 demonstrates the reduction in airflow temperature with increasing distance from the heat source for both aluminium and VCHS. Localised temperature data is presented as a percentage of maximum airflow temperature $\left(T_{L} / T_{M a x}\right)$ at various mass flow rates with a single heat source of 60 Watts.

The raw thermocouple data presents that the airflow temperature extremes are greater with the aluminium plate. The peak airflow temperature of the aluminium plate operates around $10^{\circ} \mathrm{C}$ higher than the VCHS plate. When compared in Figure 7, the VCHS base plate clearly demonstrates a more uniform temperature distribution across the width of the avionic base plate. It is also seen that by increasing the mass flow rate, the range of temperature distribution becomes greater.

It should be noted that when considering the temperature variation across the genuine avionic module, a $10 \%$ disparity is measured between circuit card 6 component temperature and the average component temperature. Figure 7 also displays a $10 \%$ difference in localised and peak temperatures across the aluminium avionic base plate. The close thermal relationship between the findings of Figure 7 and Figure 1 act to validate the experimental rig presented in this investigation.

Figure 8 demonstrates the localised heat removal efficiency across the width of the avionic base plate, expressed as a percentage of the plate averaged heat rejection efficiency measure $\left(\mathrm{Q}_{\mathrm{L}} / \mathrm{Q}_{\text {Ave }}\right)$. This testing was conducted with a heat source of 100 Watts at a mass flow rate of $37 \mathrm{Kg} / \mathrm{hr}$. This calculation represents a measure of the isothermalisation of the avionic base plate.

It can be seen that the VCHS base plate presents a localised heat removal efficiency of $\pm 1.6 \%$ of the plate average, in comparison to $+7 \%$ to $-4.5 \%$ demonstrated the aluminium plate. The total variation of heat removal efficiency is $11.5 \%$ across the aluminium avionic base plate.

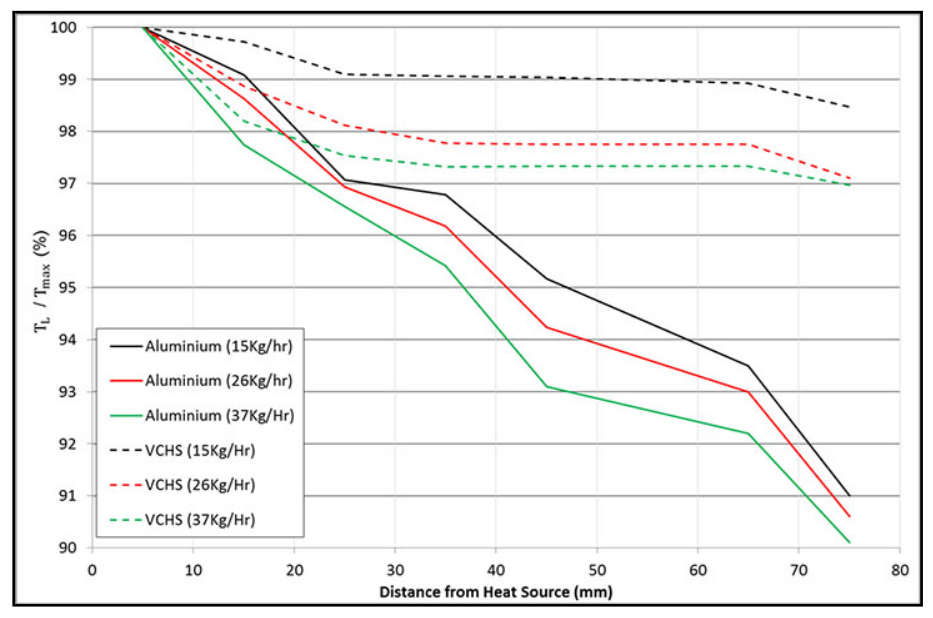

Figure 7. Localised airflow temperatures as a percentage of maximum airflow temperatures. Results for a single circuit card of 60 Watts.

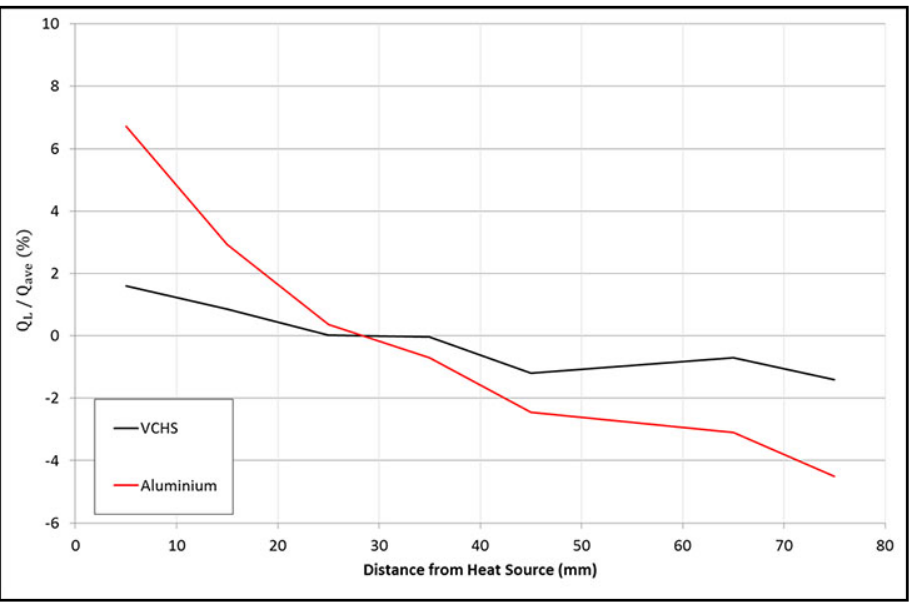

Figure 8. Localised heat removal as a percentage of plate averaged heat removal. Results for a single circuit card of 100 Watts power output and a mass flow rate of $37 \mathrm{Kg} / \mathrm{hr}$.

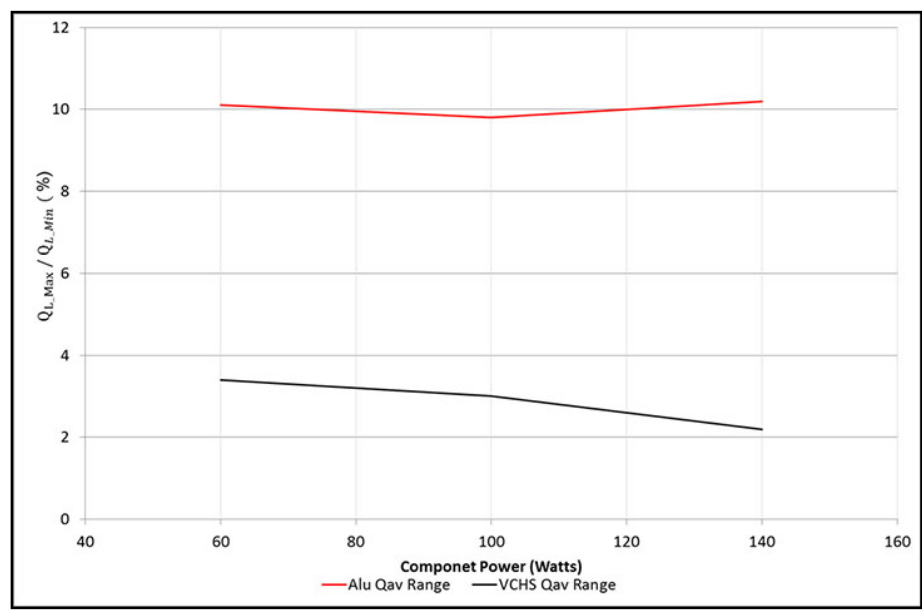

Figure 9. Mass flow rate averaged heat removal efficiency for each base plate material.

6

American Institute of Aeronautics and Astronautics 


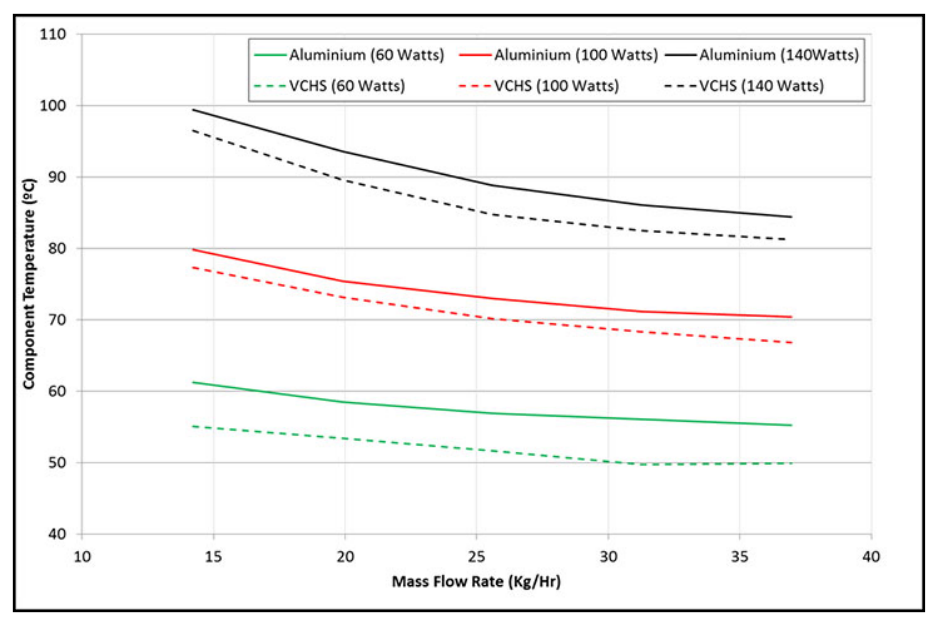

Figure 10. Component temperatures for each material across a range of mass flow rates

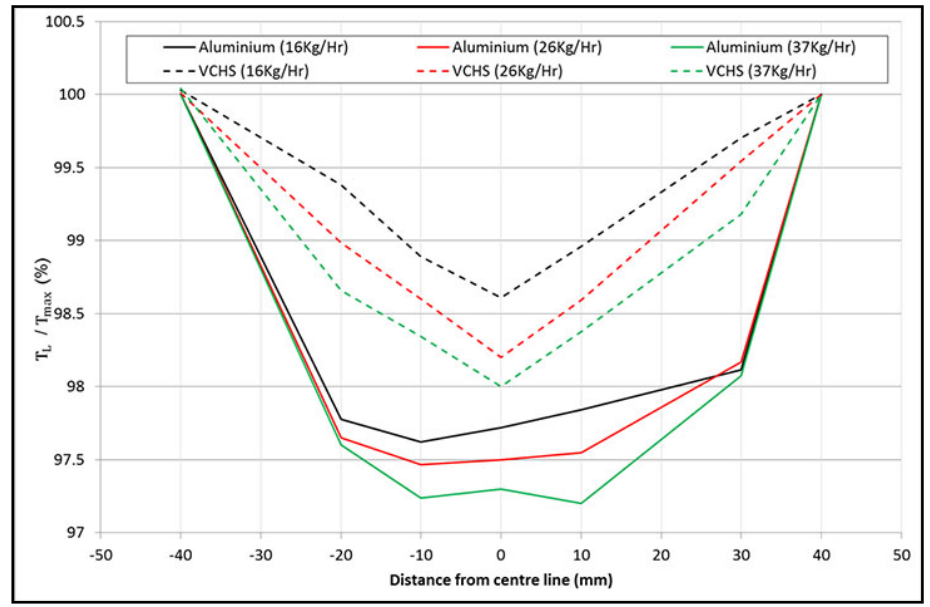

Figure 11. Localised airflow temperature as a percentage of maximum airflow temperature. Results for two circuit cards with a total power output of 60 Watts

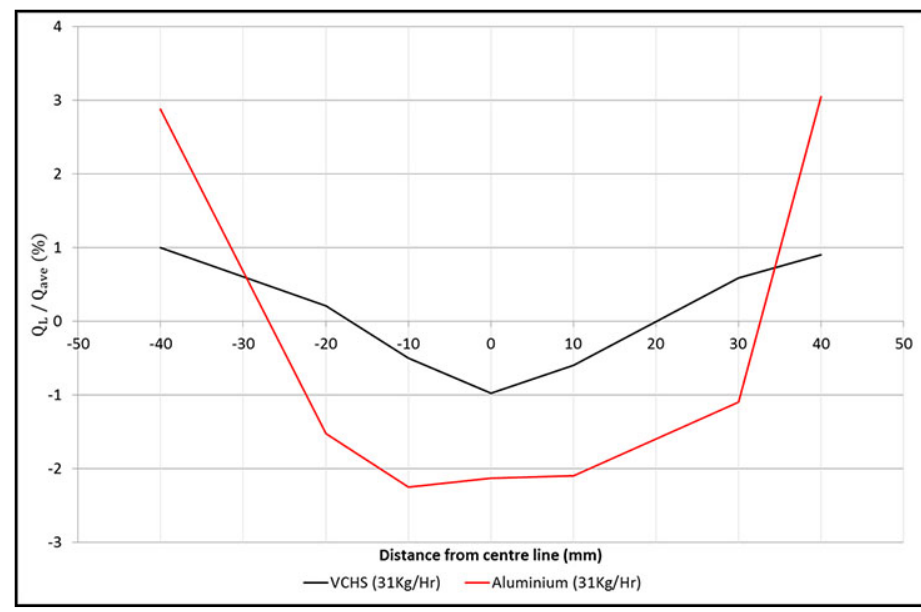

Figure 12. Localised heat removal as a percentage of plate averaged heat removal. Results for two circuit cards of 60Watts power output and a mass flow rate of $31 \mathrm{Kg} / \mathrm{hr}$.
Once a variation in power output is considered, the two plates behave as displayed in Figure 9. The range of heat removal efficiency is calculated as the maximum difference between the localised heat removal efficiency for a given mass flow rate $\left(\mathrm{Q}_{\mathrm{L} \text { Min }} / \mathrm{Q}_{\mathrm{L} \_\mathrm{Max}}\right)$. The aluminium plate shows a limited response to power output variation while the VCHS increases avionic base plate isothermality with increasing power output. As heat flux increases, the rate of vapourisation and energy transportation will continue to increase within the VCHS to a physical cycle limit, such as the boiling and sonic performance limit. Figure 9 demonstrates the applicability of distilled water as a working fluid for VCHS avionic cooling as typical avionic heat flux for a single circuit card is within the physical limits of the two phase cycle.

The improved thermal conductivity of the VCHS base plate is directly responsible for a reduction in component temperature for a fixed mass flow rate, as seen in Figure 10. It can be seen that the VCHS offers a reduction in component temperature regardless of power output or mass flow rate. When considering a single circuit card operating at $60 \mathrm{Watts,}$ the component temperature is reduced between $8 \%$ to $10 \%$ with the implementation of VCHS. As a function of the aluminium heat exchanger efficiency and the diminishing returns for increased mass flow rate with a single heat source, a disproportionately large increase of mass flow rate is required to produce a reduction in component temperature. For example, when considering a fixed component temperature of $55^{\circ} \mathrm{C}$, Figure 10 demonstrates a mass flow of $37.2 \mathrm{Kg} / \mathrm{hr}$. is required for an aluminium plate. A comparative $14.2 \mathrm{Kg} / \mathrm{hr}$. is required for the $\mathrm{VCHS}$, equating to a mass flow reduction of over $65 \%$.

\section{B. Multiple Circuit Cards}

The dummy circuit card number is increased to assess the performance of the VCHS when coupled to multiple heat sources. With the same variables considered as with a single card, Figure 11 displays a performance comparison of the base plates when considering $T_{L} / T_{\text {Max }}$, for a power output of 60 watts, equally distributed between two heat sources. The locations of both heat sources can be clearly identified at $\pm 40 \mathrm{~mm}$ from the centreline. It can be seen that the VCHS shows the localised exhaust airflow to be 
acting within $2 \%$ of the maximum recorded temperature.

When considering $Q_{L} / Q_{\text {Ave }}$, a figure for the isothermalisation of the base plates is measured, see Figure 12. The VCHS shows that localised conditions remain very close to the averaged plate performance, with a heat removal variation of $\pm 1 \%$. The aluminium plate demonstrates a heat removal variation of $+3 \%$ to $-2.5 \%$, halving the heat removal variation seen in an identical test with a single circuit card. Aluminium has an inherently high resistance to thermal energy transportation in comparison to the VCHS. By reducing the distance that the thermal energy has to travel to utilise the maximum heat transfer area, the efficiency of the aluminium base plate has been improved.

A third circuit card is added at the base plate centreline. The addition of a third card reduces the distance between the heat sources to $40 \mathrm{~mm}$. The findings with multiple circuit cards complement those of a single card, while a modest decrease in component temperature is achieved with the implementation of VCHS; the mass flow rate reduction is considerably greater, see Figure 13. Considering a component temperature of $60^{\circ} \mathrm{C}$, a mass flow rate saving of $23 \%$ is achieved with the implementation of VCHS.

As the card number is increased, the performance margins between the two materials become smaller. The distance of energy transportation to achieve complete heat exchanger fin utilisation is reduced as card number is increased. Hence, diminishing returns

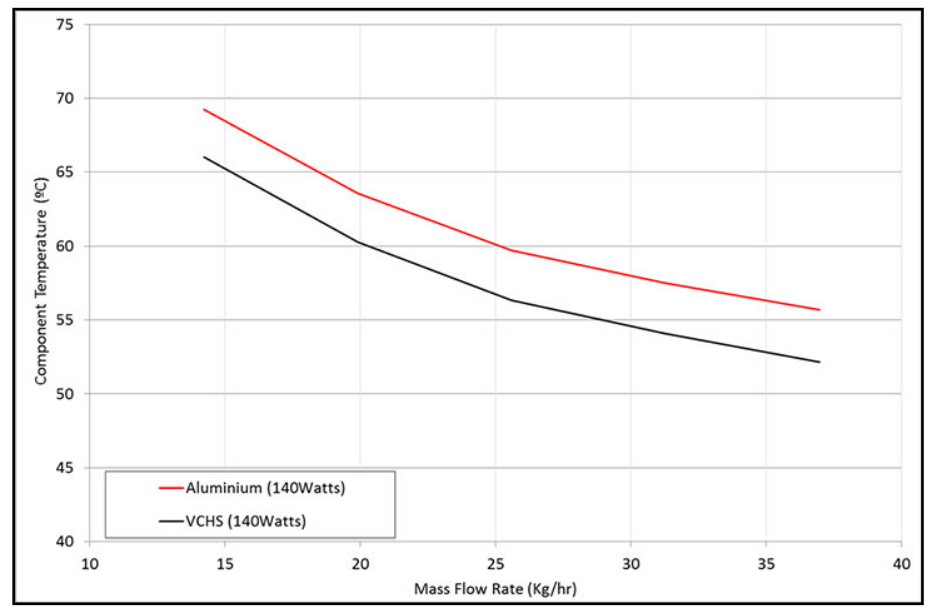

Figure 13. Component temperatures for each material base plate. Results for two circuit cards with a combined power of 140 Watts

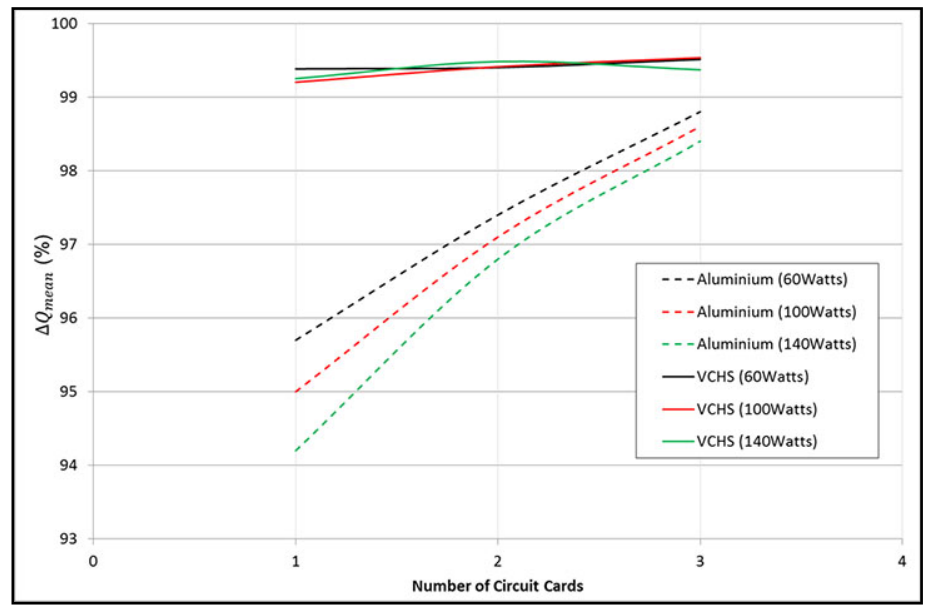

Figure 14. Mass flow rate averaged performance of each material with increasing circuit card number

can be found with the use of a high thermal conductivity material. This is further endorsed as the maximum range of $\mathrm{Q}_{\mathrm{L}} / \mathrm{Q}_{\mathrm{Ave}}$ for the aluminium plate reducing to $4 \%$ with the VCHS displaying a value of $\pm 1 \%$ when testing with 3 cards.

When considering a non-dimensional plate analysis across all operating conditions, the component $\Delta \mathrm{Q}_{\mathrm{Mean}}$ is used. The magnitude of the localised and averaged heat removal differential is calculated for all measured locations. This metric has been averaged across all mass flow rates to give a governing plate performance metric for each material at a given power output and card number, as calculated below.

$$
\Delta \mathrm{Q}_{\text {Mean }}=\Sigma\left(\mathrm{Q}_{\mathrm{L}} / \mathrm{Q}_{\mathrm{Ave}}\right)
$$

Figure 14 demonstrates two key points. The aluminium plate is highly sensitive to the circuit card number, displaying a performance improvement with increasing circuit card number. The performance of the two plates converges as the circuit card number is increased. The VCHS proves insensitive to the geometry or number of heat sources applied to the base plate.

\section{Conclusions}

This study presented the preliminary implementation of VCHS in avionic thermal management. A number of available thermal management techniques are discussed, with VCHS demonstrating the greatest match to operational challenges of the avionic sector. The conclusions from the experimental study are detailed below: 
- A representative test rig has been built for the purpose of evaluating a comparative study of a current avionic chassis and a VCHS hybrid chassis. The test rig proved a close comparison the thermal performance of a genuine avionic chassis.

- A significant improvement in the isothermalisation of the avionic base plate can be achieved by the use of a VCHS. This is especially apparent when dealing with a small and high powered heat transfer area. Across all testing, the localised heat removal was never further than 3.5\% from the averaged plate performance.

- Although the VCHS brought modest reduction in component temperature, the corresponding relationship to mass flow rate has seen a significant reduction to maintain a fixed component temperature. For a single circuit card, this improvement is between $18 \%$ to $65 \%$ across the range of mass flow rates and power outputs tested. Alternatively for a fixed mass flow rate, an increase in power output of between $8 \%$ and $22 \%$ is achieved for an identical component temperature.

- Thermal energy removal efficiency across the VCHS is insensitive to heat source geometry, power output and mass flow rate. Aluminum proved much more sensitive to the nature of thermal energy is coupled to the base plate.

The implementation of the VCHS is proven to allow a much greater integration with the larger avionic thermal management system. The insensitivity to thermal hotspots and close relationship between localised and plate averaged heat removal conditions, permits the development of a greater understanding of avionic heat exchanger performance. This technology allows the designer of the ECS flow regime to treat the avionic modules as averaged values and therefore adhere to a linear relationship between power output and required cooling mass flow.

The inability to use bespoke VCHS required the build and development of a test plate to fit the generic samples. The total thermal resistance in this system is the summation of 4 contact resistances and three material resistances. The number, type and application of each contact resistance are constant throughout all tests, as are two of the material resistances. As such, the direct comparisons between the Aluminium and VCHS form only a single element of the thermal network, reducing the potential gains from the implementation VCHS.

Further work would see the development of bespoke thin walled aluminium VCHS incorporated into a single piece avionic chassis. It is suggested this component would offer the greatest balance of thermal performance, mass, cost and reliability for improvements in avionic thermal management.

\section{Acknowledgement}

The project is co-funded by EPSRC (Engineering and Physical Sciences Research Council, UK) and BAE Systems. The samples of 2 VCHS have been supplied from Meng-Chang Tsai at the Nuclear Energy Research Facility, Taiwan.

\section{References}

\footnotetext{
${ }^{1}$ Jubran, B. A., Swiety, S. A. \& Hamdan, M. A., "Convective Heat Transfer and Pressure Drop Characteristics of Various Array Configurations to Simulate the Cooling of Electronic Modules," Int. J Heat Mass Transfer, Vol. 39, No. 16, 1995, pp. 3519 - 3529.

2 Moir, I. \& Seabridge, A., Aircraft Systems; Mechanical, electrical and avionic subsystem intergration, Longman Group UK Limited, 2001.

${ }^{3}$ Mil-E-85726,. Mil_Spec Enclosure, Standard Avionics, Forced Air Cooled, General Specification, 1986

${ }^{4}$ Williams, R., Banner, J., Knowles, I., Dube, M. Natishan, M., Pecht, M,. "An investigation of 'cannot duplicate' failures", Qual. Reliab. Engng. Int, Vol. 14, 1998, pp. 331-337

${ }^{5}$ Soderholm, P., "A system view of the no fault found (NFF) phenomenon," Reliability Engineering and System Safety, Vol. 92, 2005, pp. 1-14.

${ }^{6}$ Steadman, B., Pombo, T., Madison, I., Shively, J., Kirkland, L., "Reducing no fault found using statistical processing and an expert system”, IEEE Autotestcon, Huntsville, AL, 2002, pp 872-878.

${ }^{7}$ Wilkinson, R., Aircraft Structures and Systems. St Albans: MechAero, 2009.
} 
${ }^{8}$ Mudawar, I., “Assessment of HIgh-Heat-Flux Thermal Management Schemes," Inter Society Coference on Thermal Phoenomena, IEEE, pp. 1- 20, 2000.

${ }^{9}$ Franklin, J. L., Kramer, T.J., "Thermal design of standard avionic enclosures", 20 th Intersociety Conf. on Environemental Systems, SAE, San Diego, Califonia, pp. 1-8, 1982

${ }^{10}$ Strattan, L. "Capabilities and Limitations of Air Cooled Avionic Packages", $13^{\text {th }}$ Intersociety Conf. ON Environmental Systems, San Francisco, California, pp. 1 - 10, 1983

${ }^{11}$ Setoh, G., Tan, F. L. \& Fok, S. C.,"'Experimental studies on the use of a phase change material for cooling mobile phones", Heat and Mass Transfer, Vo. 37, pp. 1403-1410, 2010.

${ }^{12}$ Campo, D., Weyant, J., Muzyka, B., "Enhancing thermal performance in embedded computing for ruggedized military and avionics applications", $14^{\text {th }}$ ITHERM Conference, IEEE, pp.840-845.

${ }^{13}$ Naphon, P. \& Wiriyasart, S, "Study on the vapour chamber refreigerant R-141b as working fluid for HDD cooling", Internal Communications in Heat and Mass Transfer, Vol. 39, pp. 1449-1452, 2012.

${ }_{14}$ Jaworski, M., "Thermal performance of heat spreader for electronics cooling with incorporated phase change material", Applied Thermal Engineering, Volume 35, pp. 212-21, 2011.

${ }^{15}$ Reyes, M. Alonso, J. R., Arias, Velazquez, A. "Experimental and theoretical study of a vapour chamber based heat spreader for avionic applications", Applied Thermal Engineering, Vol. 37, pp. 51-59, 2012. 